\title{
MULTIDÃO PODE SUBSTITUIR CLASSE OPERÁRIA NOS DIAS DE HOJE?
}

por Sadi Dal Rosso

HARDT, Michael; NEGRI, Antonio. Multidão: guerra e democracia na Era do Império. Rio de Janeiro: Record, 2005. $530 \mathrm{p}$

O pensamento social contemporâneo requer dos autores, hoje mais do que nunca, que se proponham a pensar o presente, a analisar aquilo que está acontecendo na sociedade sob os nossos olhos e debaixo de nossos pés, dada a velocidade das transformações em curso. Os filósofos políticos Michael Hardt e Antonio Negri encaram esta tarefa nos dois últimos livros publicados. Tanto Império quanto Multidão são obras que se destinam a pensar aspectos do presente: no primeiro, a forma da soberania; no segundo, a classe social. São autores polêmicos pela atualidade de seu pensamento, pelas propostas de interpretação que apresentam e pelas críticas de que são alvo.

Multidão: guerra e democracia na Era do Império, publicado no Brasil pela editora Record em 2005, é um volumoso livro de 530 páginas, organizado em três partes. A primeira tem por objeto o estado de guerra continuada da era contemporânea. A segunda propõe a idéia de multidão como forma da nova classe social. E a terceira estuda a noção de democracia, tomando-a como projeto da multidão e analisando suas condições de possibilidade.

Não é pequena a ambição dos autores: “O conceito de multidão pretende repropor o projeto político de luta de classes lançado por

Professor do Departamento de Sociologia da UnB 
Marx" (p. 146). Assumem postura semelhante à de I. Mészáros que, no livro Para além do Capital, estabelece o objetivo de continuar e completar a arquitetura de Marx. As duas grandes obras e os dois grandes autores retomam a empreitada de analisar a sociedade sob a ótica das contradições, da luta de classes e do conflito social, decorridas duas décadas da dissolução da União Soviética e da desintegração do regime do Socialismo real na Europa, Ásia e África. O recurso a elementos da teoria marxista aparece nas obras menos como doutrina e mais como necessidade de atualização de um pensamento produzido há mais de um século e meio em condições sociais, políticas e econômicas diferentes das de hoje.

Antes de se elegerem o termo multidão, Hardt e Negri contam a peripécia filosófica pela qual passaram à procura de uma categoria que pudesse representar o conceito em que tinham de conceber conjuntamente o uno e o múltiplo. Vários termos se apresentam como possíveis candidatos ao papel de representação da idéia conjunta de unidade e pluralidade. O sujeito povo retém a noção de unidade, mas não opera com a noção de pluralidade. Ao contrário, os sujeitos massa, turba, populacho, plebe não são unidades que agem por conta própria. Multidão para os autores permite conjugar conjuntamente unidade e pluralidade, sendo um sujeito social que se reúne em torno daquilo que tem em comum.

A multidão é "formada por todos aqueles que trabalham sob o domínio do capital, e, assim, potencialmente como a classe daqueles que recusam o domínio do capital” (p. 147). Essa noção ampla incorpora os sujeitos sociais envolvidos com o trabalho, qualquer que seja seu tipo. No conceito cabem múltiplos sujeitos sociais explorados economicamente e oprimidos socialmente: operários industriais, proletários, camponeses, trabalhadores por conta própria, desempregados, subempregados, a classe que vive do trabalho, trabalhadores flexíveis dos trabalhos imateriais e trabalhadores imateriais. A menção deste último grupo requer que seja explicitada a noção de trabalho imaterial, uma categoria imprescindível para o raciocínio e repleta de controvérsias. 
O trabalho imaterial compreende os trabalhos que resultam em produtos imateriais, isto é, frutos da ação do intelecto, do afeto ou de ambos. Nova na argumentação é a tese de que o trabalho imaterial é hegemônico relativamente aos demais trabalhos. Nos séculos XIX e $\mathrm{XX}$, o trabalho industrial foi hegemônico. Impôs sua lógica, como tendência. Ao final do século XX, o papel de hegemonia passa para o trabalho imaterial, que, de certa forma, modela e transforma todos os demais trabalhos materiais.

Os trabalhos imateriais são produtivos, produzem valores. Mas esses valores não se deixam mensurar pela medida de tempo de trabalho médio socialmente necessário, critério empregado para definir o conceito de valor de troca. O problema da imensurabilidade dos trabalhos imateriais não é um problema específico da teoria do valor, pois também o é para a economia capitalista. Como remunerar uma atividade do intelecto? Como remunerar uma atividade afetiva? Qual a correspondência em dinheiro de um produto intelectual ou de um produto afetivo? Para solucionar o impossível, as empresas, os grandes negócios e os governos pagam de acordo com horas trabalhadas, parâmetro que conduz a consentimento e a acordo. Não deixa de ser uma arbitrariedade, uma postura descabida pagar segundo uma medida aquilo que não tem medida alguma. Em seu limite, o argumento conduz à idéia de que nenhum trabalho é remunerado adequadamente, mesmo aplicando-se o critério de tempo médio socialmente necessário. Nenhum trabalho material reduz-se apenas a uma operação manual, a um movimento do corpo. Mesmo o trabalho mais material contém a participação incomensurável do intelecto e do afeto do trabalhador, os quais não são mensuráveis pelas horas ativas. O trabalho é imensurável. Como estabelecer, portanto, o critério de sua remuneração? Possivelmente, o critério deva ser procurado em outras paragens, como a necessidade, a remuneração suficiente e adequada para o ser humano viver ou a repartição igualitária da riqueza geral produzida pela sociedade entre seus membros.

A tese do trabalho imaterial não se descola da teoria do valor trabalho. Antes, expande-a, alarga-a e permite alcançar as bordas 
de ação do ser humano em suas capacidades físicas, intelectuais e afetivas, retendo no cerne a proposição de que em torno do trabalho travam-se as lutas sociais. A sustentação da teoria do valor trabalho implica dificuldades teóricas para os autores quando tratam de incorporar lutas de resistência de segmentos não necessariamente organizados em torno do eixo das relações de trabalho, como as lutas das mulheres, os movimentos pela diversidade sexual, de raça, de defesa do meio ambiente e de caráter anti-bélico (p. 288). Como um conceito estruturado sobre o eixo do trabalho pode encontrar pontos de convergência comum com movimentos de luta e de resistência fundados em torno de outros princípios de organização social, de tal modo que estes outros movimentos não sejam entendidos fora ou, $o$ que seria pior, antagônicos às lutas da multidão?

O conceito de multidão propicia um salto e carrega muita esperança por buscar um ponto comum nas múltiplas lutas de resistência. $\mathrm{O}$ que há de comum nas diversas lutas de resistência que pode colocar os agentes sociais do mesmo lado do terreno? O que há de comum entre trabalhadores da indústria, trabalhadores imateriais, trabalhadores agrícolas, desempregados, migrantes, movimento negro, movimento feminista, movimento gay, movimento ambientalista, que os possa colocar no mesmo barco e cujas diversas lutam podem convergir para um bem comum maior de todos os grupos?

A noção de comum não equivale exatamente à noção de público. Talvez a imagem que mais as aproxima seria a distinção entre bem público e bem comum. Público contrapõe-se à apropriação privada. Público é aquilo que faz parte da comunidade e é administrado pelo Estado. Na economia globalizada existe uma tendência generalizada de entregar ao interesse privado todas as esferas controladas pelo poder público. O comum está para além do público e do privado. O comum parte da noção de que muitos dos mais importantes bens de que usufruímos na vida são comuns e só podem ser produzidos em comunidade, a exemplo da comunicação, da produção da subjetividade, da linguagem, dos gestos, idéias, conhecimentos, imagens, afetos, relações sociais e formas de vida. Grande parte 
do trabalho imaterial contemporâneo consiste na produção de atos de afeto e atos de conhecimento, a produção da subjetividade. Argumento semelhante é desenvolvido por André Gorz no livro $O$ imaterial.

"Esta noção de comum é a base de um projeto político pósliberal e pós-socialista" (p. 383). Como assim? Por que a economia e a sociedade estão se organizando cada vez mais na forma de redes que produzem elementos essenciais da vida social. A organização em redes permite a capacidade de tomada de decisões pela multidão de agentes diferenciados. Não se coloca, portanto, mais um projeto político revolucionário de tomada do poder por um grupo organizado que impõe seu modelo centralizado para toda a coletividade. A multidão, no seu agir cotidiano, produz a capacidade de tomar decisões próprias independentes. Esta capacidade de tomada de decisões autônomas permite pensar num projeto político democrático que não se reduza a noção de revolução por uma vanguarda e um partido ideologicamente organizado.

O livro Multidão é instigante e intrigante. É instigante à medida que coloca um problema de atualidade, buscando indícios para entendê-la. Os autores podem muito bem estar equivocados em suas concepções, mas apresentam a indiscutível vantagem de manter o olhar fixado no presente, empregando categorias que podem dar conta dos processos em andamento na sociedade. Decididamente, Hardt e Negri pensam sobre o presente e a sociedade em transformação. Que possibilidades nos apresentam a sociedade de guerra em que estamos imersos no presente e o trabalho em profunda mutação?

A obra é intrigante porque não consegue apaziguar e convencer integralmente o leitor. Consegue colocar um desafio em sua mente o desafio de perscrutar o mundo contemporâneo, mas não consegue convencer integralmente o leitor de que está tratando de uma utopia. Por isso, a obra não é um novo Manifesto Comunista, como chegou a ser aventado por comentaristas apressados.

O trabalho do analista é sempre de descer mais a fundo. Começando por dirigir sua observação para o lugar de fala dos 
autores. O lugar de fala é também o lugar de ver o mundo, de concebêlo e de pensar suas mudanças. $\mathrm{O}$ 'cantinho do mundo', de que falava Marx para analisar o capitalismo em formação, é o 'cantinho do mundo' representado pelo olhar lançado a partir do Império e para o Império Global. Mas sempre a partir de um cantinho do mundo localizado no interior do Império. Não em sua imensa, indestrutível e imperscrutável periferia. Assim sendo, temos que perguntar se um olhar lançado a partir de um cantinho do mundo situado nas bordas do centro do Império - por mais promissor que seja em termos conceituais e filosóficos - , tem a capacidade de pensar a multidão em seu sentido mais universalista, mundialista, globalista. Será que contém fôlego suficiente para incorporar na interpretação o Brasil, Guiné-Bissau e Bangladesh, ao lado de Estados Unidos e Europa? Será que a fervente realidade desses países da periferia que anseiam por superar formas aviltantes de exploração do trabalho pode ser compreendida pelo conceito de multidão? Será que mostra capacidade de incorporar todos os importantes sujeitos sociais organizados hoje em movimentos das mais distintas formas e modalidades? Em que medida a multidão que foge ao desemprego e à falta de trabalho em Governador Valadares, enfrentado o inferno solar e arenoso dos desertos do Novo México e de Arizona para poder transpor os muros de câmeras e de aço que vedam o acesso livre ao centro do Império mundial, são contemplados pelo conceito de multidão?

Hardt eNegripercebem oproblema de incorporara diversidade. Tanto assim que conseguem produzir uma elaboração primorosa sobre o trabalho imaterial do campesinato como protótipo da livre concepção e da livre resolução de problemas. Os camponeses são representantes da luta pela defesa da livre apropriação genética das sementes, portanto do comum. Os camponeses não são mais vistos como 'saco de batatas' que necessita da guia do grande timoneiro. Os camponeses, como bem mostra a organização do Movimento dos Trabalhadores Sem Terra no Brasil, são capazes de agir por conta própria na busca do comum.

Mas nem todos os migrantes que são expulsos de Governador Valadares são camponeses no sentido clássico do termo. Podem 
ser até mesmo descendentes de camponeses, como a maioria dos cidadãos habitantes das pequena e médias cidades brasileiras. São pessoas empregadas algumas, desempregadas outras, com trabalhos temporários ainda outras mais, vendedores autônomos, fornecedores de bens e de serviços. Como são compreendidos os autônomos, os vendedores ambulantes das pequenas e das grandes cidades, na concepção da Multidão formulada? Os autores respondem relativamente à produção e comércio de artesanato e encontram dificuldade em relação aos ambulantes urbanos. Mas como estes são explorados economicamente e sofrem a perseguição legal da polícia por pressão dos comerciantes estabelecidos, não é difícil colocálos do lado da multidão dos que são explorados nas mais diversas formas de expropriação do que lhes é comum.

Um aspecto altamente positivo do livro Multidão consiste no aprendizado junto a movimentos sociais das mais diversas ordens, espelhando uma preocupação teórica em absorver ensinamentos derivados das experiências concretas. Uma lista incompleta precisa mencionar os movimentos de libertação nacional, os movimentos urbanos, os movimentos de camponeses, o Movimento dos Sem Terra, o Movimento Zapatista, os movimentos em defesa dos atingidos por barragens, os movimentos das mulheres, o Fórum Social Mundial, a revolta de Berlim em 1953, a revolta do gueto de Varsóvia, sovietes e conselhos operários na União Soviética, sindicatos, sindicalismo dos movimentos sociais, o movimento italiano dos Macacões Brancos, protestos contra o G-8 em Seattle, em Gênova e outros lugares, movimentos globais de protesto, protestos contra a globalização, guerrilhas, Intifada e outras experiências não apenas dos países capitalistas desenvolvidos como também de regiões como América Latina, África, Ásia (Índia). Tal listagem contém, implicitamente, deslocamentos. Não parece ser intenção negar espaço para o movimento sindical, mas demonstrar a novidade aportada pela prática dos movimentos sociais. A novidade pode ser vista de muitos ângulos e dois merecem destaque. Primeiramente, a forma de atuação em rede e não mais sob direção centralizada. Em segundo lugar, o princípio do aprendizado democrático. Os 
novos movimentos sociais trazem em seu interior sementes de uma forma de organização democrática, não mais aquela do comando centralizado, expressa por movimentos revolucionários históricos e, sim, outra maneira de democracia participativa em que os grupos aportam suas diversidades e encontram elementos comuns de decisão. A idéia de democracia é um dos princípios de organização dos movimentos sociais, sendo possível pensá-la como aspiração universal da multidão.

Entre as críticas ao conceito de multidão e à formulação teórica que o sustenta, sobressai aquela de que é uma pura abstração, descolada da realidade do trabalho ou da realidade dos movimentos sociais. A noção de multidão encontra dificuldade para fornecer uma explicação convincente de que os movimentos de guerra, de guerrilha e de outros tipos de ataques, constituam ações que expressam o desejo de democracia. As guerras no Afeganistão, no Iraque e a recente guerra de Israel contra os palestinos que implicou na invasão do Líbano (2006) apontam para movimentos de ordenamento espacial do Império Norte-Americano, estabelecimento de hegemonia regional, menos a vontade de construir processos democráticos, em que as possibilidades de participação nas decisões se coloquem como rotina. 